\title{
The Role of EGFR-TK Inhibition in Non-Small Cell Lung Cancer
}

\author{
Giuseppe Giaccone \\ Division of Medical Oncology, Vrije Universiteit Medical Center, Amsterdam, The Netherlands
}

In this issue of ONKOLOGIE, Reck and Gatzemeier [1] describe their experience with gefitinib, an epidermal growth factor receptor tyrosine kinase inhibitor (EGFR TKI), in patients with advanced non-small cell lung cancer (NSCLC). In particular they describe 32 patients who benefited from the treatment. These results were obtained within a large compassionate use program of this agent. The major response rate reported (4\%) is low, but consistent with similar reports of unselected patients treated within the same program [2]. These results are valid in that they reflect more closely clinical practice and experience than clinical research studies, where much stricter entry criteria and evaluations are required than in every day practice. Obviously patients who are less fit and elderly patients have been treated within this program as well as patients with brain metastases. We know that performance status is an important prognostic factor, not only for response to chemotherapy, but also for response to gefitinib [3].

Major responses are often associated with particular patient characteristics, such as never-smoker status, adenocarcinoma histology, female sex and East Asian race. In the report by Reck and Gatzemeier indeed the majority of the 32 responders were female, had adenocarcinoma histology and 7 were never smokers - for 13 patients this information was not available. Interestingly these clinical characteristics are also associated with the presence of mutations in the ATP binding domain of the EGFR gene [4]. It is still not known why these particular lung cancers have EGFR mutations, but clearly these do not represent the majority of the lung cancers that are diagnosed. Although mutations cannot predict major response to treatment with EGFR TKI in all cases, they are highly predictive. Presence of amplification may also add useful information and be of help in selecting patients for treatment with these agents. In a recent report from the BR21 study, which compared erlotinib, another EGFR TKI, and best supportive care, in patients with advanced NSCLC who failed at least one chemotherapy, mutation analysis, FISH and immunohistochemistry were performed [5]. FISH analysis clearly demonstrated a good predictivity for response and also survival in univariate analysis, as did also immunohistochemistry. However, in multivariate analysis, survival after treatment with erlotinib was not influenced by the status of EGFR expression, the number of EGFR copies, or EGFR mutations. Prospective studies are needed in order to better assess the comparative and possibly additive value of these tests. In the report by Reck and Gatzemeier no biological assessment has been made, but this could certainly add to the emerging information from several groups. The implementation of mutation analysis is certainly, however, more cumbersome than more standard pathology techniques, such as FISH and immunohistochemistry, although probably less prone to subjective interpretation of the results. However, it is apparent that direct sequencing can be less sensitive on paraffin embedded material than some other methods, such as SSCP [6].

It is clear that we need proper selection criteria in order to most optimally use these agents, which have been developed as targeted agents against a well known molecule present in tumor cells at higher levels than in normal tissues. This will allow for highest benefit in selected patients and to spare the others an unsuccessful treatment. This issue may be even more important in the combination with chemotherapy, as so far in randomized studies gefitinib and erlotinib have failed to improve survival. From mutation analysis of subgroups of patients in two of these studies, it is apparent that there are groups of patients who clearly do not draw benefit from this combination; it even may be detrimental to them. The reasons for these results are still obscure, and require further investigation. Presence of K-ras mutations is a negative factor for the combination of chemotherapy and erlotinib [7].

Of interest in the present study is that the presence of major response and prolonged stabilization of the disease were asso-

\begin{tabular}{ll}
\hline KARGER & @ 2005 S. Karger GmbH, Freiburg \\
$\begin{array}{l}\text { Fax +49 761 } 4520714 \\
\begin{array}{l}\text { E-mail Information@Karger.de } \\
\text { www.karger.com }\end{array}\end{array}$ & $\begin{array}{l}\text { Accessible online at: } \\
\text { www.karger.com/onk }\end{array}$
\end{tabular}


ciated with improvement of some symptoms. This indicates that the achievement of a stable disease may represent an improvement for the quality of life of these far advanced lung cancer patients, in addition to the major responses. These results confirm those obtained in the two pivotal studies that brought gefitinib to registration in the US $[8,9]$. This also suggests that the improvement in survival is not only achieved by the major responses but also by the stable diseases.

\section{References}

1 Reck M, Gatzemeyer U: EGFR tyrosine kinase inhibitors in non-small cell lung cancer: report of a 3-year compassionate use experience with gefitinib in stage IIIB/IV outpatients. Onkologie 2005;28:623-627.

2 Giaccone G: Epidermal growth factor receptor inhibitors in the treatment of non-small-cell lung cancer. J Clin Oncol 2005;23:3235-3242.

3 Chiu CH, Tsai CM, Chen YM, et al: Gefitinib is active in patients with brain metastases from non-small cell lung cancer and response is related to skin toxicity. Lung Cancer 2005;47:129-138.

4 Pao W, Miller VA: Epidermal growth factor receptor mutations, small-molecule kinase inhibitors, and non-small-cell lung cancer: current knowledge and future directions. J Clin Oncol 2005;23:2556-2568.

5 Tsao MS, Sakurada A, Cutz JC, et al: Erlotinib in lung cancer - molecular and clinical predictors of outcome. N Engl J Med 2005;353:133-144.

6 Marchetti A, Martella C, Felicioni L, et al: EGFR mutations in non-small-cell lung cancer: analysis of a large series of cases and development of a rapid and sensitive method for diagnostic screening with potential implications on pharmacologic treatment. J Clin Oncol 2005;23:857-865.

7 Eberhard DA, Johnson BE, Amler LC, et al: Mutations in the epidermal growth factor receptor and in KRAS are predictive and prognostic indicators in patients with non-small-cell lung cancer treated with chemotherapy alone and in combination with erlotinib. J Clin Oncol 2005;23:5900-5909.

8 Fukuoka M, Yano S, Giaccone G, et al: Multi-institutional randomized phase II trial of gefitinib for previously treated patients with advanced non-small-cell lung cancer. J Clin Oncol 2003;21: 2237-2246.

$\checkmark 9$ Kris MG, Natale RB, Herbst RS, et al: Efficacy of gefitinib, an inhibitor of the epidermal growth factor receptor tyrosine kinase, in symptomatic patients with non-small cell lung cancer: a randomized trial. JAMA 2003;290:2149-2158. 